\title{
CTAB Reverse Micelles as Catalysts for the Oxidation of Ascorbic Acid by $\mathrm{K}_{3}\left[\mathrm{Fe}(\mathrm{CN})_{6}\right]$
}

\author{
K. Bhargavi ${ }^{1}$, P. Shyamala ${ }^{1, *}$, P.S.S. Chakravarthi ${ }^{1}$, K.V. Nagalakshmi ${ }^{2}$ \\ ${ }^{1}$ Department of Physical and Nuclear Chemistry and Chemical Oceanography, School of Chemistry, Andhra \\ University, Visakhapatnam, AP, 530003, India. \\ ${ }^{2}$ Department of Chemistry, Gayatri Vidya Parishad College of Engineering (Autonomous), Madhurawada, \\ visakhapatnam, AP, 530048, India.
}

Received: $11^{\text {th }}$ November 2021; Revised: $4^{\text {th }}$ January 2022; Accepted: $5^{\text {th }}$ January 2022 Available online: $7^{\text {th }}$ January 2022; Published regularly: March 2022

\section{Abstract}

The oxidation of ascorbic acid by $\mathrm{K}_{3}\left[\mathrm{Fe}(\mathrm{CN})_{6}\right]$ was studied in reverse micellar systems composed of CTAB (Cetyltrimethylammonium bromide), and it was found the observed first order $\left(k_{1(\mathrm{aq})}=5.2 \times 10^{-5} \mathrm{~s}^{-1}, k_{1(\mathrm{rev})}=\right.$ $61.4 \times 10^{-4} \mathrm{~s}^{-1}$ ) rate constant in reverse micellar medium is around forty times higher compared to aqueous medium under identical conditions. The rate enhancement $\left(k_{2(\mathrm{aq})}=0.9 \times 10^{-5} \mathrm{~mole}^{-1} \cdot \mathrm{dm}^{3} \cdot \mathrm{sec}^{-1}, k_{2(\mathrm{rev})}=1.75 \times 10^{-3}\right.$ mole $\left.{ }^{-1} \cdot \mathrm{dm}^{3} \cdot \mathrm{sec}^{-1}\right)$ is attributed to the large concentration effect and lower dielectric constant in the reverse micelles. The rate of the reaction increases with increase in $W=\left\{\left[\mathrm{H}_{2} \mathrm{O}\right] /[\right.$ surfactant $\left.]\right\}$ which is explained in terms of ionic strength of the water pool. The effect of surfactant concentration on rate was explained on the basis of Berezin pseudo phase model.

Copyright (C 2021 by Authors, Published by BCREC Group. This is an open access article under the CC BY-SA License (https://creativecommons.org/licenses/by-sa/4.0).

Keywords: Ascorbic acid; $\left[\mathrm{K}_{3} \mathrm{Fe}(\mathrm{CN})_{6}\right]$; CTAB (Cetyltrimethylammonium bromide); dielectric constant; reverse micelles.

How to Cite: K. Bhargavi, P. Shyamala, P.S.S. Chakravarthi, K.V. Nagalakshmi (2022). CTAB Reverse Micelles as Catalysts for the Oxidation of Ascorbic Acid by $\mathrm{K}_{3}\left[\mathrm{Fe}(\mathrm{CN})_{6}\right]$. Bulletin of Chemical Reaction Engineering \& Catalysis, 17(1), 157-162 (doi: 10.9767/bcrec.17.1.12732.157-162)

\section{Introduction}

The water droplets solubilized in the reverse micelles forms a water pools and shows different physical properties from those of bulk water. The properties of the solubilised water are dependent on a $W=\left\{\left[\mathrm{H}_{2} \mathrm{O}\right] /[\right.$ surfactant $\left.]\right\}$ parameter. Examples of physical properties which different from ordinary bulk water are low activity, high nucleophilicity, low dielectric constant and high ionic strength, etc. The dielectric constant in the case of cationic surfactant like CTAB (Cetyltrimethylammonium bromide) re-

* Corresponding Author.

Email: shyamalapulipaka06@gmail.com (P. Shyamala);

Telp: +919949042258 verse micelles is nearer to that of methanol at low $W$ values [1]. In the case of anionic surfactant like AOT (Aerosol Orange T) polarity of reverse micelle is between methanol and water [1-3]. The increase in $W$ value leads to increase in micro polarity (or dielectric constant) and reaches that of bulk water $[4,5]$. In the case of ionic surfactant, $W$ value regulates the concentration of the polar head groups of the surfactants and its counter ion concentrations. Ionic strength in a reverse micelle is the effective concentration of counter ion of the surfactant at a particular $W$. A variation of $W$ between 4.0 and 16.0 involves changes in ionic strength between 20 to $4 \mathrm{M}$ which also effects rate of reaction. Since all the above mentioned properties of the 
water in the reverse micelles are different in $\mathrm{CTAB} / \mathrm{CHCl}_{3} / \mathrm{Hexane}$, the rates of reactions are also expected to be different than that of conventional aqueous medium.

In studies of reactions in reverse micelles involving water-soluble reactants, the reactants are confined to the water pool. The volume of the water pool is around $0.01 \mathrm{~mL}$ while the total overall volume is $10 \mathrm{~mL}$. Since the reactants are present in the water pool at a microscopic level, the concentration of reactants with respect to water pool is around 100 times more than that compared to whole volume. This leads to a huge concentration effect. Consequently, a concentration scale is defined in order to interpret data in terms of comparisons of reactivity in reverse micelles and bulk solvent media. In the kinetic investigation of reactions take place only in water pool, effective concentrations in water pool is considered instead of overall volume as follows formula $\left\{[\text { Reactant }]_{\text {eff }}\right.$ $\left.=[\text { Reactant }]_{\text {overall }} / f\right\}$, where, $f=$ volume of water pool / (volume of water pool + volume of solvent) $[6,7]$.

Since reverse micelles involve a water /organic medium interface, they closely resemble the microenvironment of the living cells and can be considered as model system for biological studies / experiments at molecular levels. They can also solubilise all kinds of substrate molecules, hydrophilic, hydrophobic, and amphiphilies. Ascorbic acid is a very important antioxidant in biological systems and undergoes oxidation with reactive oxygen species and transition metals [8-10]. The redox chemistry of ascorbic acid is important in human nutrition [11]. The auto oxidation of ascorbic acid by oxygen in the presence of transition metals $(\mathrm{Cu}(\mathrm{II}) / \mathrm{Fe}(\mathrm{III}))$ leads to loss of ascorbic acid activity [11,12]. The kinetics of Oxidation of ascorbic acid by hexacyanoferrate(III) in aqueous perchloric acid medium have been reported earlier [13] Since reverse micelles are a good medium to mimic biological conditions, we have taken up a kinetic study of the oxidation of ascorbic of ascorbic acid by $\mathrm{K}_{3}\left[\mathrm{Fe}(\mathrm{CN})_{6}\right]$ in reverse micellar medium and the results are reported in this paper. We have earlier found that the rates of aquation of tris-2, 2'-bipyridyl iron(II) [14], base hydrolysis of tris-1,10'phenanthroline iron(II) [15], oxidation of iodide

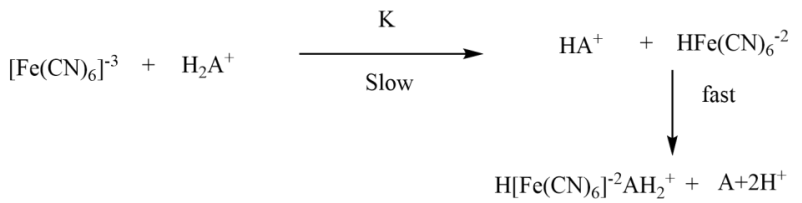

Scheme 1. Oxidation of ascorbic acid by $\mathrm{K}_{3}\left[\mathrm{Fe}(\mathrm{CN})_{6}\right]$ by $\mathrm{V}(\mathrm{V})$ [16], and reduction of toluidine blue by ascorbic acid [17] in the presence of CTAB reverse micelles, were also different in the presence of reverse micelles as reported elsewhere.

\section{Materials and Methods}

\subsection{Preparation of CTAB Reverse Micelles}

CTAB (Cetyltrimethylammonium bromide reverse micellar solution $(0.1 \mathrm{M})$ was prepared by dissolving $3.64 \mathrm{~g}$ of CTAB in a mixture of chloroform and hexane (3:2 ratios) for a 100 $\mathrm{mL}$ solution. $10 \mathrm{~mL}$ of $0.1 \mathrm{M} \mathrm{CTAB}$ was taken and then $0.02 \mathrm{~mL}$ of $\mathrm{K}_{3}\left[\mathrm{Fe}(\mathrm{CN})_{6}\right]$ was added from a stock solution of $0.25 \mathrm{M}$. The reaction was initiated by adding $0.02 \mathrm{~mL}$ of ascorbic acid from a stock solution of $2 \mathrm{M}$. $W$ was varied by changing the volume of water in the range (0 to 0.1094 ) to get $W$ value (3.33 to 16.6). The kinetic study of oxidation of oxidation of ascorbic acid by $\mathrm{K}_{3}\left[\mathrm{Fe}(\mathrm{CN})_{6}\right]$ was carried out under pseudo-first order conditions, i.e., $\left[\mathrm{H}_{2} \mathrm{~A}^{+}\right]>>\left[\mathrm{K}_{3}\left[\mathrm{Fe}(\mathrm{CN})_{6}\right]\right.$. The reaction were monitored by measuring the decrease in the absorbance of $\left[\mathrm{K}_{3}\left[\mathrm{Fe}(\mathrm{CN})_{6}\right]\right.$ at $420 \mathrm{~nm}$ using a Shimadzu-1800 spectrophotometer. Out of two reactants $\mathrm{K}_{3}\left[\mathrm{Fe}(\mathrm{CN})_{6}\right]$ and $\mathrm{H}_{2} \mathrm{~A}, \mathrm{H}_{2} \mathrm{~A}$ has no absorbance in range $400-700 \mathrm{~nm}$. The absence of $\mathrm{H}_{2} \mathrm{~A}$ was confirmed by chloroauric test [18].

\section{Results and Discussion}

The reaction between $\mathrm{K}_{3}\left[\mathrm{Fe}(\mathrm{CN})_{6}\right]$ and $\mathrm{H}_{2} \mathrm{~A}^{+}$ in $\mathrm{CTAB} / \mathrm{Chloroform} /$ Hexane/Water mixtures follows first order kinetics with respect to $\mathrm{K}_{3}\left[\mathrm{Fe}(\mathrm{CN})_{6}\right]$ as observed by the linear plots between log of absorbance $\left\{\right.$ due to $\mathrm{K}_{3}\left[\mathrm{Fe}(\mathrm{CN})_{6}\right]$ \} vs. time, under the conditions, $\left\{\left[\mathrm{HA}^{-}\right]_{0}>>\right.$ $\mathrm{K}_{3}\left[\mathrm{Fe}(\mathrm{CN})_{6}\right]_{0}$. In the present of $\mathrm{K}_{3}\left[\mathrm{Fe}(\mathrm{CN})_{6}\right]$, it exists in the protonated form $\left\{\mathrm{H}^{+} \mathrm{K}_{3}\left[\mathrm{Fe}(\mathrm{CN})_{6}\right]\right\}$ and ascorbic acid exists in the unionised. The mechanism was given under Scheme 1 .

The pseudo first order rate constant is directly proportional to $\left[\mathrm{H}_{2} \mathrm{~A}^{+}\right]$indicating first order kinetics with respect to $\mathrm{H}_{2} \mathrm{~A}$ (Table 1) (Figure 1). Since reverse micelles contains large concentration of bromide ion to compare

Table 1. Effect of varying $\left[\mathrm{H}_{2} \mathrm{~A}\right]$ on the observed rate constants $\left(k^{\prime}\right) ; \mathrm{K}_{3}\left[\mathrm{Fe}(\mathrm{CN})_{6}\right]=5.0 \times 10^{-4} \mathrm{M}$; $[\mathrm{CTAB}]=0.1 \mathrm{M} ; \mathrm{T}=302 \mathrm{~K})$.

\begin{tabular}{ccc}
\hline \multirow{2}{*}[\mathrm{H}_{2}\mathrm{A}]{$_{\mathrm{o}} \times 10^{2}$} & \multicolumn{2}{c}{$k_{1} \times 10^{5}$} \\
\cline { 2 - 3 } & $W=4.44$ & $W=8.88$ \\
\hline 0.2 & 1.074 & 1.98 \\
0.6 & 2.303 & 2.59 \\
1.0 & 3.454 & 3.852 \\
1.4 & 4.989 & 5.12 \\
1.8 & 6.141 & 6.52 \\
\hline
\end{tabular}


rate of reaction in aqueous media and reverse micellar medium, kinetics runs were performed in aqueous medium in presence of bromide ion. It was found that as concentration of bromide ion increases the rate constant decreases and a plot of the pseudo first order constant $k_{1}$ versus $1 /\left[\mathrm{Br}^{-}\right]$was found to be linear as shown in (Table 2).

\subsection{Effect of Variation of $W$ and CTAB Concen- trations}

The first order rate constant $\left(k_{1}\right)$ has been determined over a wide range of $W(3.33-16.6)$ at constant [CTAB] and also at different Concentrations of CTAB (Table 3). At constant [CTAB], second order rate constant $\left(k_{2}=\right.$ $\left.k_{1} /\left[\mathrm{H}_{2} \mathrm{~A}\right]_{\text {eff }}\right)$ increases with $W$. This is because with increase in $W$, the ionic strength decreases, and lower ionic strength favours cationanion reaction. The attenuation of special properties of water pools (like low dielectric constant) takes place at around $W=4.44$ and the $\mathrm{k}_{2}$ values are governed only by change in ionic strength [16-20]. The effect of change of $W$ on the rate of reaction has been quantitatively correlated with change in ionic strength, as follows:

$$
k_{2}=k_{2}^{0} \frac{\gamma_{\mathrm{HA}^{+}} \gamma_{\left[\mathrm{Fe}(\mathrm{CN})_{6}\right]^{-3}}}{\gamma_{\#}}
$$

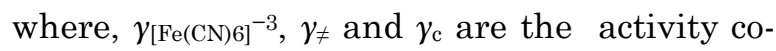
efficients of $\left[\mathrm{Fe}(\mathrm{CN})_{6}{ }^{-3}\right],[\mathrm{HA}]^{+}$and the transi-

Table 2. Effect of variation of $\left[\mathrm{Br}^{-}\right]\left(\left[\mathrm{Fe}(\mathrm{CN})_{6}\right]_{\mathrm{o}^{3+}}=5.0 \times 10^{-4} \mathrm{~mol} . \mathrm{dm}^{-3} ; W=16.6 ; \mathrm{CTAB}=0.1 \mathrm{M}\right)$.

\begin{tabular}{cccccc}
\hline $\begin{array}{c}\text { Added }\left[\mathrm{Br}^{-}\right] \\
\left(\mathrm{mol} . \mathrm{dm}^{-3}\right)\end{array}$ & $\begin{array}{c}{\left[\mathrm{Br}^{-}\right]_{\mathrm{e}}} \\
\left(\mathrm{mol} . \mathrm{dm}^{-3}\right)\end{array}$ & $\begin{array}{c}k_{(\mathrm{aq} . \mathrm{m})}^{\prime} \times 10^{5} \\
\left(\mathrm{sec}^{-1}\right)\end{array}$ & $\begin{array}{c}k_{2(\mathrm{aq} . \mathrm{m})} \times 10^{4} \\
\left(\mathrm{sec}^{-1}\right)\end{array}$ & $\begin{array}{c}k_{(\mathrm{r} . \mathrm{m}) \times 10^{3}} \\
\left(\mathrm{sec}^{-1}\right)\end{array}$ & $\begin{array}{c}k_{2(\mathrm{r} . \mathrm{m})} \times 10^{4} \\
\left(\mathrm{dm}^{3} \cdot \mathrm{mol}^{-1} \cdot \mathrm{sec}^{-1}\right)\end{array}$ \\
\hline 0.1 & 3.33 & 3.85 & 38.5 & 1.38 & 4.15 \\
0.16 & 5.33 & 1.95 & 12.18 & 1.84 & 3.46 \\
0.39 & 13.0 & 1.15 & 8.8 & 2.30 & 1.76 \\
0.6 & 20.3 & 0.92 & 4.5 & 3.22 & 1.59 \\
\hline
\end{tabular}

Table 3. Observed first order $\left(k^{\prime}\right)$ and second order rate constants $\left(k_{2}\right)$ for the oxidation of ascorbic acid by $\mathrm{K}_{3}\left[\mathrm{Fe}(\mathrm{CN})_{6}\right] .\left(\left[\mathrm{H}_{2} \mathrm{~A}\right]=1.8 \times 10^{-2} \mathrm{M} ; \mathrm{K}_{3}\left[\mathrm{Fe}(\mathrm{CN})_{6}\right]=5.0 \times 10^{-4} \mathrm{M} ; \mathrm{T}=302.0 \mathrm{~K}\right)$.

\begin{tabular}{|c|c|c|c|}
\hline$W$ & [CTAB] & $\begin{array}{l}k_{1} \times 10^{4} \\
\left(\sec ^{-1}\right)\end{array}$ & $\begin{array}{c}k_{2} \times 10^{3} \\
\left(\mathrm{~mol}^{-1} \mathrm{dm}^{3} \mathrm{sec}^{-1}\right) \\
\end{array}$ \\
\hline 3.33 & \multirow{6}{*}{0.05} & 61.4 & 0.91 \\
\hline 4.44 & & 49.8 & 0.98 \\
\hline 6.66 & & 38.3 & 1.15 \\
\hline 8.88 & & 26.8 & 1.47 \\
\hline 12.2 & & 18.8 & 1.63 \\
\hline 16.6 & & 10.2 & 1.83 \\
\hline 3.33 & \multirow{6}{*}{0.1} & 21.4 & 6.3 \\
\hline 4.44 & & 15.0 & 6.7 \\
\hline 6.66 & & 12.4 & 7.4 \\
\hline 8.88 & & 12.0 & 13.2 \\
\hline 12.2 & & 11.0 & 14.3 \\
\hline 16.6 & & 10.0 & 15.0 \\
\hline 3.33 & \multirow{6}{*}{0.2} & 17.2 & 10.3 \\
\hline 4.44 & & 10.5 & 10.4 \\
\hline 6.66 & & 8.99 & 10.8 \\
\hline 8.88 & & 8.60 & 22.4 \\
\hline 12.2 & & 8.33 & 25.0 \\
\hline 16.6 & & 6.63 & 26.0 \\
\hline 3.33 & \multirow{6}{*}{0.3} & 9.00 & 16.9 \\
\hline 4.44 & & 7.80 & 18.2 \\
\hline 6.66 & & 6.01 & 19.8 \\
\hline 8.88 & & 4.152 & 29.0 \\
\hline 12.2 & & 3.28 & 31.0 \\
\hline 16.6 & & 2.69 & 35.6 \\
\hline
\end{tabular}


tion state and $k_{2}{ }^{0}$ is the rate constant at zero ionic strength and the activity co efficient $\gamma_{i}$ of an ion is given by:

$$
-\log \gamma_{\mathrm{i}}=\frac{A Z_{i}^{2} \mu^{1 / 2}}{1+\mu^{1 / 2}}-\sum_{\mathrm{j}} B_{\mathrm{i}, \mathrm{j}} C_{\mathrm{j}}
$$

where, $C_{j}=$ the summation of extending overall ions concentration, $B_{\mathrm{i}, \mathrm{j}}=$ the summation of extending specific interaction parameters.

Using equations (1) and (2), it can be shown that

$$
\log k_{2}=\log k_{2}^{\mathrm{o}}-\frac{A \mu^{1 / 2}}{1+\mu^{1 / 2}}-b\left[\mathrm{Br}^{-}\right]
$$

where, $\Sigma_{j} B_{i j} C_{j}=b\left[\mathrm{Br}^{-}\right]$' $b$ ' contain the relevant specific interactions between positively charged micellar surface $(\mathrm{M})$ and $\left[\mathrm{Fe}(\mathrm{CN})_{6}\right]^{-3},\left[\mathrm{H}_{2} \mathrm{~A}\right](\mathrm{C})$ and $\mathrm{Br}^{-}$, between the singly charged transition state (\#) and $\mathrm{Br}^{-}, \mathrm{Na}^{+}$and $\mathrm{Br}^{-}$. According to equation 3 , a plot of $k_{2}$ versus $\mathrm{Br}^{-}$has to be straight line. Such a plot was obtained at three different concentrations of CTAB (Figure 2) [21-23].

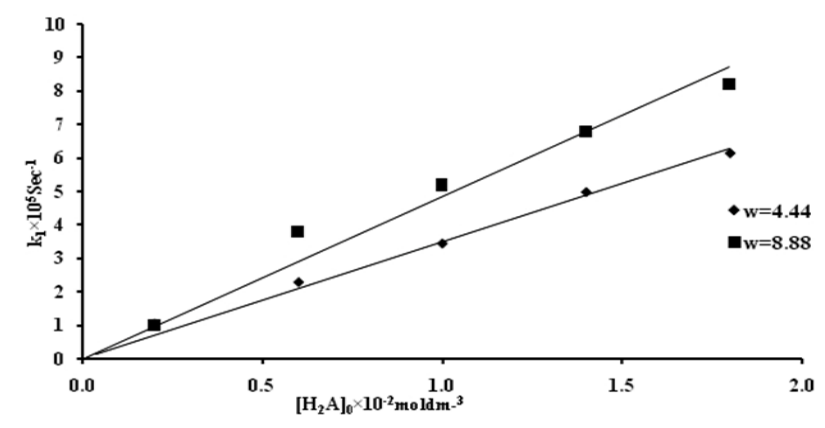

Figure 1. Effect of $\left[\mathrm{H}_{2} \mathrm{~A}\right]$ at different $W$ (from 4.44 to 8.88 ) on the oxidation of ascorbic acid by $\mathrm{K}_{3}\left[\mathrm{Fe}(\mathrm{CN})_{6}\right]$.

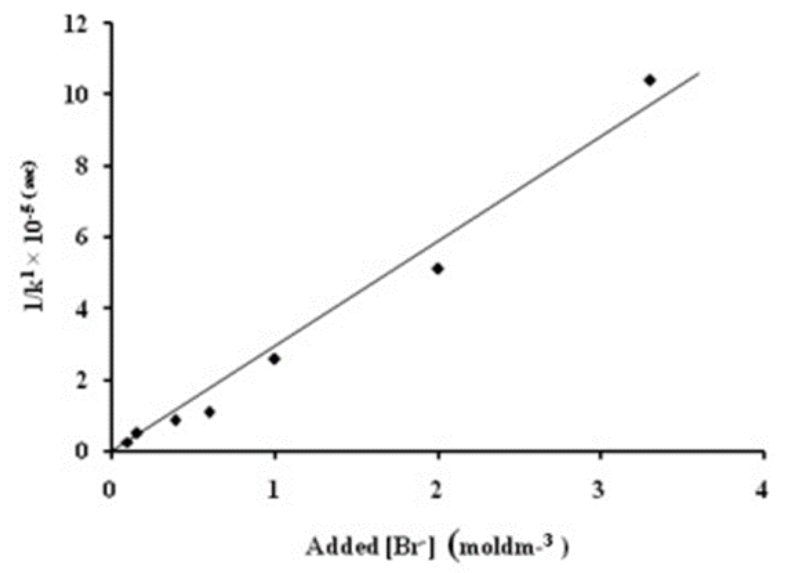

Figure 2. Effect of Variation of $[\mathrm{Br}]$ vs $1 / k_{1}$ at $W=12.2$ and $W=3.33$.

\subsection{Effect of CTAB}

With increase in CTAB concentration, at constant $W$, the second order rate constant increases. This study has been carried out in a detailed manner at two $W$ values one is the low $W$ range (3.33) and other in the high $W$ range (16.6) [23-26]. According to Berezin pseudo phase model, the second order rate constant $k_{2}$ is given by,

$$
k_{2}=\frac{k_{m} P_{\left[\mathrm{Fe}(\mathrm{CN})_{6}\right]} P_{H_{2} A^{+}} C V+k_{w}(1-C V)}{\left(1+K_{\left[\mathrm{Fe}(\mathrm{CN})_{6}\right]^{-}}+C\right)\left(1+K_{H_{2} A^{+}} C\right)}
$$

where, $K_{\{\mathrm{Fe}(\mathrm{CN}) 6]^{-3}}=P_{\mathrm{H}_{2} \mathrm{~A}^{+}} V, P_{\mathrm{H}_{2} \mathrm{~A}^{+}}$is the partition co-efficient, and $V$ is the molar volume.

$$
k_{2}=\frac{k_{m} P_{\left[\mathrm{Fe}(\mathrm{CN})_{6}\right]^{-}}+K_{\mathrm{H}_{2} A^{+}} C+k_{w}(1-C V)}{\left(1+K_{\left[\mathrm{Fe}(\mathrm{CN})_{6}\right]} C\right)\left(1+K_{\mathrm{H}_{2} A^{+}} C\right)}
$$

Since both the reactants are hydrophilic and weakly bound at the micellar surfaces,

$$
k_{2}=k_{m} P_{\left[\mathrm{Fe}(\mathrm{CN})_{6}\right]} K_{H_{2} A^{+}} C+k_{w}
$$

In the equation (5), $C V$ can be neglected in comparison to 1 in the denominator. $k_{m}$ is the rate constant of the reaction at the interface and $k_{w}$ corresponding to the entrapped water. In the present case a plot of $k_{2}$ versus $C$ was found to be linear with a positive intercept (Figure 3) giving evidence to the assumption that $1 \gg K_{\mathrm{H}_{2} \mathrm{~A}^{+}} C, \mathrm{~K}_{3}\left[\mathrm{Fe}(\mathrm{CN})_{6}\right]$. The slope corresponds to $k_{m} K_{\mathrm{H} 2 \mathrm{~A}^{+}}, \mathrm{K}_{[\mathrm{Fe}(\mathrm{CN}) 6]^{-3}}$ and intercept gives the rate constant $k_{w}$ for the reaction in the entrapped water. The value of $k_{w}\left(2.95 \times 10^{-3}\right.$ $\mathrm{min}^{-1}$ from Figure 3) is thirty three times greater than the rate constant of the reaction in aqueous medium in the absence of bromide

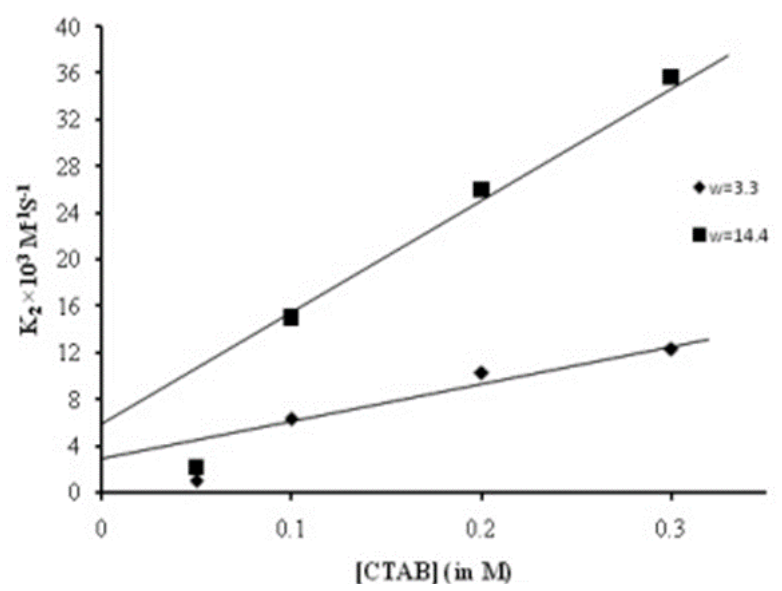

Figure 3. Effect of [CTAB] at different $W$ on the oxidation of ascorbic acid by $\mathrm{K}_{3}\left[\mathrm{Fe}(\mathrm{CN})_{6}\right]$. 
ion $\left(k_{2}=9.1 \times 10^{-5} \mathrm{~mol}^{-1} \cdot \mathrm{dm}^{3} \cdot \mathrm{sec}^{-1}\right)$. In presence of bromide ion $\left[\mathrm{Br}^{-}\right]$(Figure 4), the rate is around forty two times greater in comparison to aqueous medium. This large increase of rate in the reverse micelles illustrates the special properties of entrapped water, i.e., micro polarity at low $W$ s.

\section{Conclusion}

The pseudo first order rate constant of oxidation of ascorbic by $\mathrm{K}_{3}\left[\mathrm{Fe}(\mathrm{CN})_{6}\right]$ is forty two times faster in the $\mathrm{CTAB} / \mathrm{CHCl}_{3} /$ hexane reverse micellar medium compared to conventional aqueous medium. The significant increase is attributed to the concentration effect produced in the reverse micelles and lower micro polarity of the reverse micelles which facilitates the reaction between oppositely charged ions.

\section{Acknowledgments}

The authors (PS and $\mathrm{KB}$ ) are grateful to Ministry of Earth Sciences (MOES), National Centre for Coastal Research (NCCR) and Government of India for financial support under major project No MOES/ICMAM- PD/Supply. Order/81/2017. KVNL is thankful to the Management of Gayatri Vidya Parishad College of Engineering, Visakhapatnam for their support and encouragement.

\section{References}

[1] Michael, R., Branka, M.L., Nancy, E.L., Kenneth, W.H. (2004). Water motion in reverse micelles studied by quasi elastic neutron scattering and molecular dynamics simulations. Journal of Chemical Physics, 121, 7855-7868. DOI: $10.1063 / 1.1792592 .3$.

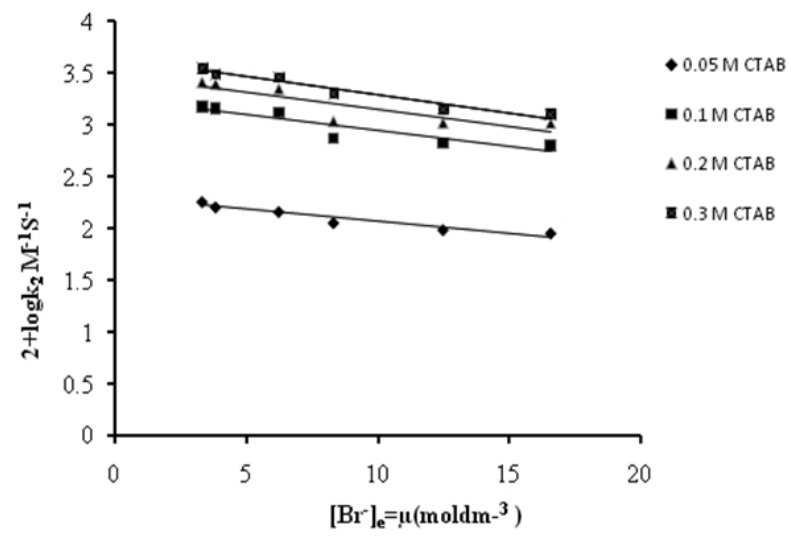

Figure 4. Effect of ionic strength $(\mu)$ (= effective bromide ion concentration $\left.\left[\mathrm{Br}^{-}\right]_{\mathrm{e}}\right)$ the oxidation of ascorbic acid by $\mathrm{K}_{3}\left[\mathrm{Fe}(\mathrm{CN})_{6}\right]$.
[2] Amanda, J.M., John, W., Melanie, M.B. (2014). NMR and molecular dynamics study of the size, shape, and composition of reverse micelles in a cetyltrimethylammonium bromide (CTAB)/n-hexane/pentanol/water microemulsion. Journal of Physical chemistry B, 118, 10767-10775. DOI: 10.1021/jp504585k.

[3] Lubica, K., Eva, M., Peter, S., Petr, S., Petr, K. (2015). Nature of CTAB/Water/Chloroform Reverse Micelles at Above- and Subzero Temperatures Studied by NMR and Molecular Dynamics Simulations. Langmuir, 31, 82848293. DOI: 10.1021/acs.langmuir.5b01776.

[4] Menger, F.M., Donohue J.A., Williams, R.F. (1973). Catalysis in water pools. Journal of American Chemical Society, 95, 286-288. DOI: $10.1021 /$ ja00782a075.

[5] Chuanyi, Y., Shaokun, T., He, Z., Deng, X. (2005). Kinetics of lipase-catalyzed hydrolysis of olive oil in AOT/isooctane/reverse micelles. Journal of Molecular Catalysis B Enzymatic, $\begin{array}{llllllllll} & 5 & 5 & 0 & 8 & - & 1 & 1 & 2 & \end{array} \quad$ D O I : 10.1016/j.molcatb.2005.06.005

[6] Johnson, M.D., Lorenz, B.B., Wilkins, P.C., Lemons, B.G., Baruah, B., Lamborn, N., Stahla, M., Chatterjee, P.B., Richens, D.T., Crans, D.C. (2012). Switching Off Electron Transfer Reactions in Confined Media: Reduction of [Co (dipic) 2 ]- and [Co(EDTA)]- by Hexacyanoferrate(II). Inorganic Chemistry, 51, 2757-2765. DOI: 10.1021/ic201247v.5.

[7] Gallie, D. R. (2013). L-ascorbic acid: A multifunctional molecule supporting plant growth and development. Scientifica, 1-24. DOI: 10.1155/2013/795964.

[8] Gallie, D.R. (2013). The role of l-ascorbic acid recycling in responding to environmental stress and in promoting plant growth. Journal of experimental botany, 64, 433-443. DOI: 10.1093/jxb/ers330.

[9] Akram, N.A., Shafq, F., Ashraf, M. (2017). Ascorbic acid-a potential oxidant scavenger and its role in plant development and abiotic stress tolerance. Frontiers in plant Science, 8, 1-9. DOI: $10.3389 /$ fpls.2017.00613.

[10] Kai, S., Jingxia, Q., Jiwei, L., Yuqing, M. (2009). Preparation and characterization of gold nanoparticles using ascorbic acid as reducing agent in reverse micelles. Journal of Materials Science, 44, 754-758. DOI: 10.1007/s10853-008-3162-4.

[11] Viktor, A.T., Tatyana, V.K., Nikolay, E.P., George, J.K. (2020). Redox Interactions of Vitamin $\mathrm{C}$ and Iron: Inhibition of the ProOxidant Activity by Deferiprone. International Journal of Molecular Science, 21, 1-16, DOI: 10.3390/ijms21113967. 
[12] Luis J.A.M., Barbosa da Ccsta, J. (1988). The Oxidation of Ascorbic Acid by Hexacyanoferrate(lll) Ion in Acidic Aqueous Media. Application of the Marcus cross-relation. Journal of Chemical Education, 65(2), 176. DOI: 10.1021/ed065p176.

[13] Venkateswarlu, G., Shyamala, P., Subba Rao, P.V., Ramakrishna, K. (2002). Kinetics of dissociation of tris-(2, 2'-bipyridyl) and tris-(1, 10-phenanthroline) iron(II) complexes in the presence of $\mathrm{OH}^{-}$in the water pools of CTAB reverse micelles. Indian Journal of Chemistry, 41A, 1410-1414.

[14] Shyamala, P., Subba Rao, P.V. (2010). Kinetics of Oxidation of Iodide by Vanadium (V): Catalysis by the Water Pools of CTAB Reverse Micelles. Kinetics and Catalysis, 51, 207-210. DOI: 10.1134/S0023158410020060

[15] Padma, M., Shyamala, P., Satyanarayana, A. Subba Rao, P.V., Asha, M. (2016). Catalytic effect of CTAB reverse micelles on reduction of toluidine blue by ascorbic acid. Indian Journal of Chemistry, 52, 221-225.

[16] Perez-Benito J.F., Arias, C. Rodriguez, R.M., Marta, R. (1998). Kinetics and mechanism of the reduction of chromium (VI) by D-ribose. New Journal of Chemistry, 22, 1445-1451. DOI: 10.1039/A803690J

[17] Schultz, R.D., Dekkar, A.O. (1956). Oxidation of Ascorbic Acid by Oxygen with Cupric Ion as Catalyst. The Journal of Physical Chemistry, 60(8), 1095-1100. DOI: 10.1021/j150542a016.

[18] Hashmi, M.H., Ayaz, A.A., Viegas, A., Subhan adil, A. (1971). Determination of Ascorbic Acid and differential detection of the vitamin and reducing sugars. MicroChemical Journal, 16(4), 645-651. DOI: 10.1016/0026$265 x(71) 90057-9$.

[19] Luisi, P.L., Straub, B.E., (1984). Biological and Technological Relevance of Amphiphilic Structures in Apolar Media. Reverse Micelles, (Eds.), Springer.
[20] Nagalakshmi, K.V., Shyamala, P. (2019). Kinetics of oxidation of $\left[\mathrm{Fe}(\text { phen })_{3}\right]^{+2}$ by persulphate: catalysis in the water pools of CTAB reverse micelles. Bulgarian Chemical Communications, 51, 494-498. DOI: 10.34049/bcc.51.4.4946

[21] Nagalakshmi, K.V., Shyamala, P. (2020). Acid Hydrolysis of Bis (2, 2'; 6', 2"-Terpyridyl) Iron (II) Complex in the Water Pools of CTAB/Hexane/Chloroform Reverse Micelles-A Kinetic Study in Confined Medium. Bulletin of Chemical Reaction Engineering \& Catalysis, $\quad 15(3), \quad 853-860$. D O I : 10.9767/bcrec.15.3.8425.853-860.

[22] Bhargavi, K., Shyamala, P., Padma, M., Nagalakshmi, K.V. (2021). Kinetic Study of SN2 Reaction between ParanitrophenylBenzoate and Hydrazine in the Presence of CTABReverse Micelles. Bulletin of Chemical Reaction Engineering \& Catalysis, 16(4), 744-751. DOI: $10.9767 /$ bcrec.16.4.11036.744-751

[23] Sadhana, S., Das, S.P., Patnaik, A.K. (2012). Kinetics and Mechanism of Oxidation of LAscorbic Acid by Pt(IV)(aq) in Aqueous Hydrochloric Acid Medium. Advances in Physical Chemistry, 2012, 143734. DOI: $10.1155 / 2012 / 143734$.

[24] Kelemu, L., Sargeson, A.M., Elding, L.I., (2000). Kinetics and mechanism for reduction of oral anticancer platinum (IV) dicarboxylate compounds by L-ascorbate ions. Journal of Chemical Society, Dalton Transactions, 7, 1167-1172. DOI: 10.1039/A909484I

[25] Hayakawa, K., Minami, S., Nakamura, S. (1973). Kinetics of the Oxidation of Ascorbic Acid by the Copper (II) Ion in an Acetate Buffer Solution, Bulletin of Chemical Society of Japan, 46, 2788-2791. DOI: 10.1246/bcsj.46.2788.

[26] Sarah, M., Ogren, P.J. (1999). Kinetics of Methylene Blue Reduction by Ascorbic Acid, Journal of Chemical Education, 76, 970-973. DOI: 10.1021/ed076p970. 